\title{
ADIAR OU NÃO AS ELEIÇÕES MUNICIPAIS EM RAZÃO DA PANDEMIA? UMA PROPOSTA INTERMEDIÁRIA DE SOLUÇÃO CONSTITUCIONAL
}

\author{
Bernardo de Lima Barbosa Filho \\ Walles Henrique de Oliveira Couto ${ }^{2}$ \\ Alexandre Moura Alves de Paula Filho ${ }^{3}$
}

\section{RESUMO:}

A crise sanitária provocada pelo coronavírus ameaça o calendário do pleito municipal previsto constitucionalmente para o primeiro domingo de outubro de 2020. Adiar ou não as eleições municipais em razão da pandemia? Diante da iminente necessidade de adiamento do pleito, este trabalho apresenta o estudo das normas constitucionais que regem a matéria, identifica (in)viabilidades das soluções até então propostas, e tem como objetivo apresentar sugestão de alteração normativa que concilie saúde pública com a legitimidade das eleições. Como conclusão, surge uma proposta intermediária de solução: autorização constitucional para, se preciso, realizar o adiamento parcial do pleito.

PALAVRAS-CHAVE: pandemia; aglomeração; eleição; adiamento; legitimidade.

\section{TO POSTPONE MUNICIPAL ELECTIONS OR NOT DUE TO THE PANDEMIC? AN INTERMEDIATE PROPOSAL FOR A CONSTITUTIONAL SOLUTION}

\begin{abstract}
:
The sanitary crisis caused by the coronavirus threatens the constitutionally scheduled municipal election calendar for the first Sunday of October 2020. To postpone municipal elections or not due to the pandemic? Facing the imminent need to postpone the election, this paper presents the study of the constitutional norms that rule the matter, identifies (in)viabilities of the proposed solutions until then, and aims to present a suggestion of normative alteration that reconciles public health with the legitimacy of elections. As conclusion, there is an intermediate proposal for a solution: constitutional authorization to, if necessary, make the partial postponement of the elections.
\end{abstract}

KEYWORDS: pandemic; crowding; election; postponement; legitimacy.

\footnotetext{
${ }^{1}$ Mestre em administração pública pela Escola Brasileira de Administração Pública e de Empresas da Fundação Getúlio Vargas (FGV/EBAPE); Especialista em direito eleitoral pelo Centro Universitário Maurício de Nassau (Uninassau). Advogado. E-mail: blbfcel@yahoo.com.br

${ }^{2}$ Mestrando em direito pela Universidade Católica de Pernambuco (Unicap); Especialista em direito eleitoral pelo Centro Universitário Maurício de Nassau (Uninassau) e em direito municipal pela Universidade Anhanguera (Uniderp). Advogado. E-mail: wallescouto@ hotmail.com

${ }^{3}$ Mestre em direito pela Universidade Católica de Pernambuco (UNICAP); Especialista em direito médico e da saúde pela Faculdade de Ciências Humanas e Exatas do Sertão do São Francisco (FACESF). Advogado. E-mail: adepaulafl@hotmail.com
} 


\section{Introdução}

O mundo luta contra o coronavírus (Covid-19). No Brasil, várias medidas sanitárias foram adotadas para o enfrentamento da pandemia, inclusive a proibição de aglomeração, o que será apresentado mais detalhadamente adiante. Enquanto isso, já superado o primeiro quadrimestre do ano, o Calendário Eleitoral das Eleições 2020 continua em pleno vigor, caminhando para as fases do pleito municipal que implicam ajuntamento de pessoas.

Convenção partidária, campanha porta a porta, comícios, reuniões e o dia da votação são exemplos de aglomerações que, por viabilizarem a disseminação do Covid-19, estão proibidas. Surge o problema do presente trabalho: adiar ou não as eleições municipais em razão da pandemia? O objetivo é apresentar uma proposta de solução que concilie saúde pública com a legitimidade das eleições, resguardando a ordem constitucional, bem como o debate necessário com toda população para a escolha do Prefeito, Vice-Prefeito e Vereadores.

A Constituição Federal do Brasil de 1988 impositivamente determina o calendário das eleições municipais:

\footnotetext{
Art. 29. O Município reger-se-á por lei orgânica, votada em dois turnos, com o interstício mínimo de dez dias, e aprovada por dois terços dos membros da Câmara Municipal, que a promulgará, atendidos os princípios estabelecidos nesta Constituição, na Constituição do respectivo Estado e os seguintes preceitos:

I - eleição do Prefeito, do Vice-Prefeito e dos Vereadores, para mandato de quatro anos, mediante pleito direto e simultâneo realizado em todo o País;

II - eleição do Prefeito e do Vice-Prefeito realizada no primeiro domingo de outubro do ano anterior ao término do mandato dos que devam suceder, aplicadas as regras do art. 77, no caso de Municípios com mais de duzentos mil eleitores;

III - posse do Prefeito e do Vice-Prefeito no dia $1^{\circ}$ de janeiro do ano subseqüente ao da eleição;
}

O Tribunal Superior Eleitoral (TSE), no uso da prerrogativa constante no artigo 23, inciso IX, do Código Eleitoral, expediu onze Resoluções para regulamentar as eleições de 2020, instrumentos normativos publicados em 27 de dezembro de 2019. Até então, o Brasil estava em plena normalidade, em termos de saúde pública.

Em 30 de janeiro de 2020, a Organização Mundial da Saúde (OMS) declarou emergência de saúde pública de interesse internacional pelo surto do novo coronavírus. Até o final de abril do mesmo ano, o mundo, incluindo o Brasil, sofreu os efeitos da crescente 
pandemia, como resumidamente descreve a Organização Pan-Americana de Saúde (OPAS), em seu sítio eletrônico:

- A Organização Mundial da Saúde (OMS) declarou, em 30 de janeiro de 2020, que o surto da doença causada pelo novo coronavírus (COVID-19) constitui uma Emergência de Saúde Pública de Importância Internacional - o mais alto nível de alerta da Organização, conforme previsto no Regulamento Sanitário Internacional. Em 11 de março de 2020, a COVID-19 foi caracterizada pela OMS como uma pandemia.

- Foram confirmados no mundo 3.090.445 casos de COVID-19 (71.839 novos em relação ao dia anterior) e 217.769 mortes (9.797 novas em relação ao dia anterior) até 30 de abril de 2020.

- O Brasil é um dos países com transmissão comunitária da COVID-19 e confirmou 85.380 casos e 5.901 mortes pela doença até a tarde do dia 30 de abril de 2020 (ORGANIZAÇÃO PAN-AMERICANA DA SAÚDE, 2020).

A Lei Federal $n^{0} 13.979$, de 06 de fevereiro de 2020, que "dispõe sobre as medidas para enfrentamento da emergência de saúde pública de importância internacional decorrente do coronavírus responsável pelo surto de 2019”, estabeleceu em seu artigo $3^{\circ}$ que as autoridades poderão adotar, no âmbito de suas competências, dentre outras, medidas como o isolamento e quarentena.

Em controle de constitucionalidade da Lei acima indicada, o Plenário do Supremo Tribunal Federal (STF), de forma unânime, referendou decisão liminar concedida no bojo da ação direta de inconstitucionalidade (ADI) $n^{\circ} 6.341$ do Distrito Federal, que reconheceu a competência concorrente de estados e municípios sobre saúde pública (BRASIL, 2020-B).

Em Pernambuco, por exemplo, o Governo do Estado expediu o Decreto $n^{\circ} 48.809$, de 14 de março de 2020, determinando uma série de medidas restritivas. Entre estas, destaca-se para o objeto do presente trabalho, a proibição de concentração de pessoas em número superior a $10(\mathrm{dez})^{4}$, "enquanto perdurar o estado de emergência em saúde causado pelo coronavírus"

Até março de 2020, reafirmou-se que calendário eleitoral das Eleições 2020 está sendo cumprido. A ministra Rosa Weber considerava, naquele momento, prematuro o debate sobre

\footnotetext{
${ }^{4}$ Art. $3^{\circ}$-D Fica suspensa, no âmbito do Estado de Pernambuco, a concentração de pessoas em número superior a 10 (dez), salvo nos casos das atividades essenciais referidas no $\$ 2^{\circ}$, ou daquelas expressamente excepcionadas nos decretos estaduais que tratam da emergência em saúde pública de importância internacional decorrente do coronavírus. (Redação alterada pelo art. $1^{\circ}$ do Decreto $n^{\circ} 48.882$, de 3 de abril de 2020.)

5 Art. 12. Este Decreto entra em vigor na data sua publicação e produzirá efeitos enquanto perdurar o estado de emergência em saúde causado pelo coronavírus.
} 
adiamento do pleito no atual momento, pontuando que a velocidade da evolução do quadro exigia permanente reavaliação das providências (BRASIL, 2020-D).

O discurso da Corte Superior Eleitoral mudou no início de maio de 2020, conforme pronunciamento do presidente eleito do TSE, Ministro Luís Roberto Barroso, divulgado pela Associação dos Magistrados Brasileiros (AMB):

\begin{abstract}
"Por minha vontade, nada seria modificado porque as eleições são um rito vital para a democracia. Portanto, o ideal seria nós podermos realizar as eleições. Porém, há um risco real, e, a esta altura, indisfarçável, de que se possa vir a ter que adiá-las" (ASSOCIAÇÃO DOS MAGISTRADOS BRASILEIROS, 2020)
\end{abstract}

Para responder adequadamente o problema proposta, adotou-se metodologia mista. Inicialmente, será feita revisão de literatura através do estudo das normas constitucionais que regem a matéria, arrolando as propostas de soluções aventadas. Em seguida, passa-se a análise empírica de natureza qualitativa, identificando, dentre os cenários possíveis, uma proposta de lege ferenda que concilie saúde pública com a legitimidade das eleições. Essa construção, vale frisar, não se esgota após uma definição acerca de possível adiamento ou não e como ele se dará, servindo como crítica caso a decisão tomada se dê de maneira de modo desarrazoado.

\title{
2. Dos direitos e garantias fundamentais postos em xeque com o adiamento ou não das eleições
}

O debate da relação entre Direito e democracia está posto. Contudo, faz-se necessário firmar a compreensão de que a política está umbilicalmente vinculada ao debate mundial firmado acerca de saúde pública e economia, os dois principais pontos atingidos pela pandemia. Neste sentido, importante consideração faz José Jairo Gomes (2020, p. 4):

\footnotetext{
O universo político abrange a direção do Estado nos planos externo e interno, a gestão de recursos públicos, a definição e o desenvolvimento de políticas públicas, a implementação de projetos sociais e econômicos, o acesso a cargos públicos, a realização de atividades legislativas e jurisdicionais, a resolução de conflitos entre indivíduos e grupos, entre outras coisas.
}

Em outras palavras, os direitos e garantias fundamentais relacionados ao tema proposto, todos, em maior ou menor intensidade, vinculam-se ao tema político. As Eleições 
2020, portanto, se adiada ou não, da forma que for conduzida pelos poderes constituídos, implicará nos direitos políticos ${ }^{6}$, mas também terá reflexos na saúde pública e consequentemente na economia, posto que o Poder Executivo e Legislativo Municipal têm decisiva atuação nos destinos dos interesses locais, na dicção do artigo 30, inciso I, da Constituição Federal.

Em um primeiro bloco, o direito à vida é primeiro indicado no caput do caro artigo $5^{\circ}$ da Magna Carta, tendo uma primazia que dispensa maiores considerações para o desenvolvimento do presente trabalho. Decorrente do direito à vida, o direito à saúde é constitucionalmente posto:

Art. 196. A saúde é direito de todos e dever do Estado, garantido mediante políticas sociais e econômicas que visem à redução do risco de doença e de outros agravos e ao acesso universal e igualitário às ações e serviços para sua promoção, proteção e recuperação.

Os "Considerandos" a seguir transcritos, invocados no já mencionado Decreto $\mathrm{n}^{\circ}$ 48.809/2020 do Estado de Pernambuco, bem apresentam o contexto da saúde pública:

CONSIDERANDO que a Organização Mundial da Saúde - OMS classificou, em 11 de março de 2020, que o COVID-19, nova doença causada pelo novo coronavírus (denominado SARS-CoV-2), é uma pandemia;

CONSIDERANDO a altíssima capacidade de contágio por cada pessoa doente com o COVID-19 na transmissão desse vírus;

CONSIDERANDO que, a cada dia, têm se confirmado novos casos de pessoas contaminadas com o COVID-19 em todo o território nacional;

CONSIDERANDO, em particular, que o COVID-19 apresenta elevada taxa de mortalidade que se agrava entre idosos, pessoas com doenças crônicas e imunodeprimidas;

CONSIDERANDO a Portaria $\mathrm{n}^{\circ}$ 188, de 3 de fevereiro de 2020, do Ministério da Saúde, que declara Emergência em Saúde Pública de importância Nacional (ESPIN) em decorrência da Infecção Humana pelo novo Coronavírus (2019$\mathrm{nCoV}$ ), bem como a Portaria $\mathrm{n}^{\circ} 356$, de 11 de março de 2020, que dispõe sobre a regulamentação e operacionalização do disposto na Lei no 13.979, de 6 de fevereiro de 2020, que estabelece as medidas para enfrentamento da emergência de saúde pública de importância internacional decorrente do coronavírus (COVID-19);

CONSIDERANDO a recomendação do Ministério da Saúde, transmitida em 13 de março de 2020, para que, durante o atual período de emergência na saúde pública, fossem adiados ou cancelados eventos de massa governamentais, esportivos, culturais, e/ou políticos, bem como cruzeiros turísticos;

\footnotetext{
${ }^{6}$ Entabulados no Capítulo IV, do Título II (Dos Direitos e Garantias Fundamentais) da Magna Carta.
} 
As circunstâncias acima fundamentaram a decretação de isolamento social, na defesa do direito fundamental à vida e a saúde.

Em um segundo bloco, de forma não desvinculada do primeiro, a pandemia também ameaça a soberania popular que, nos termos do artigo 14 da Constituição Federal, "será exercida pelo sufrágio universal e pelo voto direto e secreto, com valor igual para todos". Dois cenários se apresentam.

O não adiamento da Eleição 2020, com sua realização nos moldes estabelecidos na pré-pandemia, só será possível se a guerra contra o coronavírus for vencida até o mês de julho de 2020, o que é pouco provável que aconteça. Pesquisadores da Universidade de Minnesota alertam para possíveis ressurgimentos de surtos ao longo de 18 a 24 meses (VEJA, 2020).

Revisitando a história, verifica-se que o Brasil já teve eleição em tempo de pandemia. Foi em 1918, enquanto a gripe espanhola assolava o país, o Presidente eleito, Rodrigues Alves, morreu da referida gripe, antes de tomar posse. Eis o registro feito pelo Senado Federal:

O filme de terror teve início há 100 anos, quando a gripe espanhola invadiu o país. Uma violenta mutação do vírus da gripe veio a bordo do navio Demerara, procedente da Europa. Em setembro de 1918, sem saber que trazia o vírus, o transatlântico desembarcou passageiros infectados no Recife, em Salvador e no Rio. No mês seguinte, o país todo está submerso naquela que até hoje é a mais devastadora epidemia da sua história.

A gripe espanhola, como indicam os discursos acima, domina os debates do Congresso. As falas dos parlamentares integram o acervo dos Arquivos do Senado e da Câmara dos Deputados, em Brasília, e mostram como o Brasil de 1918 se comporta diante da doença.

Assim como outros prédios públicos do país, o Senado e a Câmara, no Rio (que tem o status de Distrito Federal), passam vários dias fechados. Não há funcionários - muitos convalescem e outros tantos morreram. Após um período combalido, o senador Paulo de Frontin (DF) é recebido com festa na volta à Casa.

- Tendo sido vítima da espanhola, Sua Excelência está aí rijo, cumprindo seus deveres com aquela atividade rara que todos lhe reconhecemos discursa o senador Victorino Monteiro (RS).

Nem o presidente da República é poupado. Rodrigues Alves, eleito em março de 1918 para o segundo mandato, cai de cama "espanholado" e não toma posse. O vice, Delfim Moreira, assume interinamente em novembro, à espera da cura do titular. Alves, porém, morre em janeiro de 1919, e uma eleição fora de época é convocada (BRASIL, 2018). 
Em face da pandemia e de tudo até aqui apresentado, o não adiamento da Eleição 2020 se apresenta como uma alternativa inviável, para o resguardo da saúde da população, em atendimento às recomendações e normas que impedem aglomeração.

O segundo cenário, o adiamento da Eleição 2020, é o cerne do presente trabalho, apresenta uma série de obstáculos constitucionais os quais passaremos debater. As seguintes perguntas se mostram desafiadoras: é possível a ampliação do atual mandato dos Prefeitos, Vice-Prefeitos e Vereadores? Se sim, durante quanto tempo? Se não, quem ocupará os cargos do Poder Executivo e Legislativo municipal a partir de 2021, caso não ocorra as eleições em 2020? Com o adiamento das eleições, como ficaria o princípio da anterioridade eleitoral, constitucionalmente estabelecido ${ }^{7} \mathrm{E}$ as inelegibilidades superadas ou adquiridas no período posterior ao prazo de registro de candidatura inicialmente estabelecido pela Lei Federal $n^{\circ}$ $9.504 / 97^{8}$ ? Os demais prazos do calendário eleitoral, inclusive no tocante às condutas vedadas ${ }^{9}$, teriam como referência a nova data das eleições? E se houver mais de um adiamento, como resguardar a segurança jurídica do pleito? É possível mitigar a propaganda eleitoral, em prejuízo sobretudo ao cidadão, que tem o direito de ser bem informado para poder escolher o seu representante? Seria possível restringir a propaganda eleitoral apenas às redes sociais, em um cenário onde a massa não possui tecnologia ou aptidão ou cultura para utilização de tal meio? Haveria tempo hábil e segurança jurídica para desenvolver uma forma de votação remota, em substituição à urna eletrônica?

Além do direito à vida e saúde, o povo brasileiro tem direito constitucional: ao Estado Democrático de Direito, incluindo o pluralismo político $^{10}$; à informação, à livre locomoção e a se reunir pacificamente ${ }^{11}$; ao alistamento eleitoral ${ }^{12}$; e, com muita ênfase para o escopo do presente trabalho, tem direito ao "voto direto, secreto, universal e periódico"13.

\footnotetext{
${ }^{7}$ Art. 16. A lei que alterar o processo eleitoral entrará em vigor na data de sua publicação, não se aplicando à eleição que ocorra até um ano da data de sua vigência.

${ }^{8}$ Art. $8^{\circ}$ A escolha dos candidatos pelos partidos e a deliberação sobre coligações deverão ser feitas no período de 20 de julho a 5 de agosto do ano em que se realizarem as eleições, lavrando-se a respectiva ata em livro aberto, rubricado pela Justiça Eleitoral, publicada em vinte e quatro horas em qualquer meio de comunicação.

${ }^{9}$ Artigo 73 e seguintes da Lei $n^{\circ}$ 9.504/97.

${ }^{10}$ Art. $1^{\circ}$ A República Federativa do Brasil, formada pela união indissolúvel dos Estados e Municípios e do Distrito Federal, constitui-se em Estado Democrático de Direito e tem como fundamentos: (...) V - o pluralismo político. Parágrafo único. Todo o poder emana do povo, que o exerce por meio de representantes eleitos ou diretamente, nos termos desta Constituição.

${ }^{11}$ Art. $5^{\circ}$ Todos são iguais perante a lei, sem distinção de qualquer natureza, garantindo-se aos brasileiros e aos estrangeiros residentes no País a inviolabilidade do direito à vida, à liberdade, à igualdade, à segurança e à propriedade, nos termos seguintes: (...) XIV - é assegurado a todos o acesso à informação e resguardado o sigilo da
} 
De um lado, o direito fundamental à vida e à saúde. De outro, também caros direitos vinculados à democracia, à ordem constitucional no tocante à composição dos Poderes, no resguardo do Estado de Direito. Diante do conflito de direitos fundamentais verificado no adiamento da Eleição 2020, necessária a ponderação defendida por Robert Alexy (2008, p. 117), para que tais direitos sejam realizados na maior medida possível, diante das possibilidades fáticas e jurídicas existentes.

Como visto, a discussão é ampla. Para adequação ao que propõe o presente artigo, necessário um corte metodológico, pelo que se restringe o estudo com a análise da inviabilidade das Propostas de Emenda Constitucional (PEC) em tramitação e, na sequência, com a formulação de proposta intermediária de solução constitucional: adiamento parcial do pleito, o que se dará nos itens 2 e 3 a seguir.

\section{Análise da (in)viabilidade das alternativas até então apresentadas}

Dentro da perspectiva de adiamento da Eleição 2020, duas teses se apresentam na comunidade jurídica: a primeira, advoga a prorrogação dos mandatos dos Prefeitos, VicePrefeitos e Vereadores eleitos em 2016, por mais dois anos, unificando com o calendário eleitoral das eleições gerais de 2022 (BRASIL, 2020-A); a segunda, mais cautelosa, prever a prorrogação, se imprescindível em razão da pandemia, tão somente pelo período necessário à regularização da crise sanitária.

A validade do voto proferido pelo povo brasileiro em 2016 expira em 31 de dezembro de 2020, nos termos do já citado artigo 29, I, da Constituição Federal. Em sentido contrário ao prazo de quatro anos do mandato, há propostas de emenda à Constituição (PEC) para adiar as

fonte, quando necessário ao exercício profissional; XV - é livre a locomoção no território nacional em tempo de paz, podendo qualquer pessoa, nos termos da lei, nele entrar, permanecer ou dele sair com seus bens; XVI - todos podem reunir-se pacificamente, sem armas, em locais abertos ao público, independentemente de autorização, desde que não frustrem outra reunião anteriormente convocada para o mesmo local, sendo apenas exigido prévio aviso à autoridade competente;

${ }^{12}$ Art. 14. A soberania popular será exercida pelo sufrágio universal e pelo voto direto e secreto, com valor igual para todos, e, nos termos da lei, mediante: (...) $\S 1^{\circ} \mathrm{O}$ alistamento eleitoral e o voto são: I - obrigatórios para os maiores de dezoito anos; II - facultativos para: a) os analfabetos; b) os maiores de setenta anos; c) os maiores de dezesseis e menores de dezoito anos.

${ }^{13}$ Art. 60. A Constituição poderá ser emendada mediante proposta: (...)§ $4^{\circ}$ Não será objeto de deliberação a proposta de emenda tendente a abolir: (...) II - o voto direto, secreto, universal e periódico; 
eleições municipais deste ano para 2022 e estender os mandatos de prefeitos e vereadores até $1^{\circ}$ de janeiro de 2023.

Jaime Barreiros Neto (2020, p. 126), no artigo "Os Impactos do COVID-19 nas Eleições 2020 e a Proposta de Unificação do Calendário Eleitoral” pondera:

Para que a democracia cumpra bem o seu papel de regime norteador da liberdade e da dignidade humana, não basta que tenhamos eleições. É necessário que exista igualdade política, participação efetiva do povo nas decisões, transparência pública, liberdade de informação e de expressão, educação cívica, controle da ação dos governantes, normalidade e legitimidade do poder de sufrágio popular, exercido de forma universal, sem restrições desarrazoadas.

Aderimos à posição de Barreiros Neto (2020, p. 131) que conclui pela inconveniência e a inconstitucionalidade da proposta de unificação do calendário eleitoral a partir de 2022 . Segundo ele, o argumento de uma suposta vantagem da unificação do calendário eleitoral, relativo a uma provável economia substancial gerada aos cofres públicos com a realização de eleições apenas de cinco em cinco anos, não procede, uma vez que a maior parte dos gastos realizados com as eleições decorre de custos fixos, vinculados à manutenção da estrutura da Justiça Eleitoral: "Uma suposta economia de recursos seria, portanto, insignificante, em termos gerais, para o país".

O segundo é também importante argumento para não unificação das eleições reside no conflito das pautas de discussão: questões gerais versus interesse local. Neste sentido, Barreiros Neto (2020, p. 133) arremata:

Além disso, eleições municipais não devem ocorrer de forma concomitante às eleições presidenciais. O período eleitoral deve favorecer a reflexão e o amadurecimento democrático, a fim de que o povo possa, legitimamente, exercer a soberania popular. $\mathrm{O}$ calendário eleitoral, neste sentido, deve ser elaborado a partir de um objetivo principal: viabilizar a normalidade e a legitimidade do exercício da vontade soberana e autônoma do povo diante das urnas.

Não existe democracia sem entendimento esclarecido, sem informação e pensamento críticos. Confundir o eleitor com a realização, ao mesmo tempo, de eleições presidenciais, nas quais se objetiva o debate consciente da sociedade acerca de grandes temas de interesse nacional, e de eleições municipais, onde demandas e interesses locais, também de grande relevância, mas com características e objetivos completamente distintos, se constituem no motivo maior de discussão, somente atrapalha a formação do livre convencimento do eleitor, que, na maioria das vezes, tenderá ou a valorizar mais o debate e a reflexão acerca dos temas gerais, debatidos nas eleições 
presidenciais, ou a privilegiar as questões mais paroquiais, típicas do processo eleitoral municipal.

Walber Agra (2020) também é contra a unificação das eleições:

O princípio da paridade de armas no pleito eleitoral é desdobramento do cânone da isonomia, que garante a igualdade dos meios utilizados na ambiência do pleito a todos os candidatos. Postergar as eleições de modo a burlar um imperativo constitucional, privilegiará, indubitavelmente, o status quo dos governistas nos mais díspares rincões do país, em ordem a impedir as possibilidades de mudanças decorrentes dos resultados dos pleitos, no que desmerece a soberania popular, fundamento basilar do ordenamento jurídico.

Para ilustrar a inquietação acerca do tema, importante registrar que o Deputado Federal João Henrique Holanda Caldas formulou perante o TSE a Consulta nº 11551 (2020-C), de Relatoria do Ministro Og Fernandes, com os seguintes questionamentos:

1) Em caso de emergência sanitária que impeça a reunião de pessoas, e sendo o processo eleitoral permeado desse tipo de situação, existem instrumentos que possibilitem a modulação do calendário eleitoral e adequação a esse tipo de situação?

2) Em caso positivo à resposta anterior, o restante do calendário, a exemplo dos períodos de pré-campanha, alistamento eleitoral, filiação e desincompatibilização poderiam, igualmente, sofrer essa modulação?

3) Havendo a modulação a que aludem os itens antecedentes, essas alterações estariam submetidas ao princípio da anualidade de que trata o artigo $16 \mathrm{da}$ Constituição Federal?

A Consulta acima colabora com a discussão e o amadurecimento do tema. Contudo, apesar de ainda não julgada, provavelmente não será conhecida, pelas razões constantes no parecer da Assessoria Consultiva do TSE, de lavra do técnico judiciário Paulo José Oliveira Pereira, por configurar caso concreto, o que inviabilizaria a apreciação da Corte em processo de Consulta:

Verifica-se que a questão versada tem contorno de caso concreto, uma vez que o cenário atual é de comoção pública decorrente da pandemia do coronavírus, situação dotada de excepcionalidade, que tem exigido dos poderes públicos a adoção progressiva de medidas destinadas a conter a disseminação da virose. Nesse sentido, a jurisprudência remansosa deste Tribunal Superior é de não se conhecer consulta que ventila caso concreto: 
Consulta. Partido Humanista da Solidariedade/PHS. Possibilidade de remuneração de dirigentes partidários com Recursos oriundos do fundo partidário. Fundamentação. Art. 44, I, da Lei no 9096/95. Referência a caso concreto. Consulta não conhecida. (Consulta $n^{\circ}$ 1732, Rel. Designado Min. Dias Toffoli)

(...)

Não obstante se reconheça o cenário excepcional em que se encontra a sociedade brasileira, cabe sublinhar que o processo eleitoral, na sua quase totalidade, é regido por disposições legais e constitucionais, que não podem ser ignoradas sob pena de se macular a própria eleição, ante a falta de legitimidade e constitucionalidade dos atos eventualmente praticados ao arrepio das normas fundamentais.

E nesse particular vale o destaque de que o acervo normativo pátrio não traz disciplina acerca de possíveis impactos de situações excepcionais como a que ora se vivencia sobre as eleições, sendo necessário ponderar os diversos fatores que circundam a questão, para se deliberar oportunamente sobre a opção mais adequada, sem retirar do pleito a sua tão festejada legitimidade.

3. Pelo exposto, esta Assessoria opina pelo não conhecimento da consulta, sem prejuízo de outras eventuais providências que se venha a entender cabíveis, considerada a relevância da matéria.

O eventual adiamento das eleições municipais de 2020 precisa que ser antecedido de mudanças constitucionais, especificamente nas disposições transitórias, pelo prazo mais breve possível do pleito adiado, com o menor número possível de mudanças nas regras do jogo, visando, inclusive, à preservação da continuidade da administração pública.

Caminhando na tentativa de propor solução ao imbróglio, efetivamente a alternativa acima é a que melhor se harmoniza com a proporcionalidade e razoabilidade, ainda que ocorra prorrogação de mandato por alguns meses.

O problema é que ainda não houve um aprofundamento dos obstáculos constitucionais, especialmente quanto aos prazos do calendário eleitoral e quem ocuparia o Poder Executivo e Legislativo municipal a partir de $1^{\circ}$ de janeiro de 2021, na hipótese de não ocorrer as eleições em 2020.

Quanto a esta última questão, invariavelmente haveria a prorrogação temporária dos mandatos. É que a possibilidade de aplicação do artigo 80 da Constituição Federal ${ }^{14}$, fazendo com que o juiz da Comarca assumisse a Chefia do Executivo tem cabimento fático em um cenário de normalidade. Em contexto de vacância de todos os cargos de Prefeito e Vereadores do país, caso o juiz assumisse o Poder Executivo, quem ocuparia o Poder Legislativo ou

${ }^{14}$ Art. 80. Em caso de impedimento do Presidente e do Vice-Presidente, ou vacância dos respectivos cargos, serão sucessivamente chamados ao exercício da Presidência o Presidente da Câmara dos Deputados, o do Senado Federal e o do Supremo Tribunal Federal. 
mesmo o próprio Poder Judiciário. Não é demais lembrar que a separação dos poderes é cláusula pétrea, nos termos do artigo $60, \S^{\circ}$, da Constituição Federal.

Também sobre o aspecto da legitimidade, cumpre registrar que os eleitos majoritariamente em 2016 possuem a validação do voto, sendo os mais habilitados para ocupar os cargos por eles hoje exercidos, por meio de uma prorrogação feita pelo menor espaço de tempo possível.

Quanto ao calendário eleitoral em caso de adiamento da Eleição 2020, tal aspecto será abordado no item a seguir, que melhor atende à estruturação do presente trabalho.

\section{Proposta intermediária de solução: autorização constitucional para, se preciso, realizar o adiamento parcial do pleito}

Incialmente, repisamos que a situação em questão gira em torno de conflitos entre direitos fundamentais (à vida e à saúde, de um lado; à democracia, à ordem constitucional no tocante à composição dos Poderes, no resguardo do Estado de Direito, de outro). Rômulo Magalhães Fernandes (2016, p. 279 e 280) propõe o exercício hermenêutico de ponderação baseada, primordialmente, na lição de Robert Alexy (2008):

A ponderação como forma de solução de conflitos de direitos fundamentais pode ser guiada por um conjunto de princípios, tais como: o princípio da unidade do texto constitucional, da concordância prática ou harmonização e da proporcionalidade.

Robert Alexy, atento à íntima conexão entre a teoria geral dos princípios e a "máxima proporcionalidade", consegue equacionar qual valor deve preponderar num contexto de colisão de princípios constitucionais. O teórico germânico, diferente de outros autores brasileiros, adota o termo princípio da proporcionalidade, mas, sim, da "máxima de proporcionalidade", o qual representa um dever resultante de uma implicação lógica do caráter das normas, sendo esta uma das razões de não ser possível determinar um fundamento positivo da proporcionalidade no texto constitucional.

A ponderação, desse modo, pode ser o critério utilizado para alcançar ou identificar, no caso concreto, a preponderância que vai permitir limitar um dos princípios, em favor do maior aproveitamento dos valores resguardados no que com ele colide. Em outros termos, a ponderação de bens e valores apresenta-se como um eficiente critério ou método de solução de conflitos entre os diversos princípios constitucionais. 
Humberto Ávila também desenvolveu a teoria da proporcionalidade com semelhanças à de Alexy, valendo destacar o destrinche feito à regra da proporcionalidade em três exames: adequação, necessidade e proporcionalidade em sentido estrito.

No exame da adequação, ensina Ávila que "a Administração e legislador têm o dever de escolher um meio que simplesmente promova o fim" (2005, p. 117). Já a necessidade diz respeito à verificação de meios alternativos àquele inicialmente adotado pelos Poderes Legislativo ou Executivo, que promovam o mesmo fim na mesma intensidade e de modo menos restritivo aos direitos fundamentais afetados (ÁVILA, 2005, p. 122). A proporcionalidade em sentido estrito, por sua vez, "exige a comparação entre a importância da realização do fim e a intensidade da restrição aos direitos fundamentais" (ÁVILA, 2005, p. 124).

Retomemos ao tema. Qualquer previsão sobre a necessidade de adiamento da Eleição 2020 padece da certeza e clareza, tão importantes para a promoção da segurança jurídica. Reconhecemos a grande probabilidade de ter que ocorrer o adiamento. Mas quanto tempo de prorrogação é necessário?

Partindo da premissa de que a prorrogação da Eleição agendada para 04 de outubro de 2020 deve se dar pelo menor espaço de tempo possível, propomos uma alternativa que tem a pretensão de ser uma possível solução para dirimir as tantas questões constitucionais e legais postas: Proposta de Emenda Constitucional (PEC) para incluir o artigo 115 no Ato das Disposições Constitucionais Transitórias (ADCT), autorizando que o TSE, se necessário em razão da pandemia, adie as eleições municipais, determinando, outrossim, as seguintes balizas: cumprimento do calendário eleitoral, em seu formato original, até o dia 15 de agosto de 2020, suspendendo-se o calendário eleitoral a partir de então (a exceção dos prazos relativos a: processos judiciais; das regras que visam impedir o abuso de poder econômico e político; abuso de poder e uso indevido de meios de comunicação social; e condutas vedadas a agentes públicos); suspendendo a aplicabilidade dos dispositivos legais contrariados pelo sugerido artigo da ADCT, suspensão tão somente para a eleição municipal que está prevista para 2020; tudo isso enquanto perdurar o estado de emergência em saúde causado pelo Coronavírus ou até que tenhamos meios seguros de viabilizar as eleições, do ponto de vista da saúde pública e segurança jurídica.

Razões para tal sugestão: 
1) A exitosa experiência, apesar da pandemia, dos prazos da janela partidária (03 de abril) e de filiação partidária (04 de abril), que dependiam de ações predominantemente dentro do ambiente partidário, além do contato com a Justiça Eleitoral, feito de forma remota, via Sistema de filiação partidária ${ }^{15}$; por mais difícil que seja realizar uma convenção com as vedações sanitárias, o direito de reunião suprimido será amplamente compensado pela segurança jurídica que será demonstrada nos pontos a seguir.

2) Obediência ao princípio da anterioridade ${ }^{16}$ no tocante à elegibilidade. O formato sugerido afastará as discussões sobre as inelegibilidades superadas ou adquiridas no período posterior ao prazo de registro de candidatura inicialmente estabelecido pela Lei Federal $n^{\circ}$ 9.504/97, o que promoverá segurança jurídica, pelo atendimento ao disposto no artigo $14, \S 9^{\circ}$ da $\mathrm{CF}^{17}$ e disposições constantes na Lei Complementar $n^{\mathrm{o}} 64 / 90^{18}$.

3) Otimização do tempo necessário ao processamento do registro de candidaturas. O calendário eleitoral estabelece um prazo de aproximadamente 30 (trinta) dias para "que todos os pedidos de registro de candidatos a prefeito, vice-prefeito e vereador, inclusive os impugnados e os respectivos recursos, devem estar julgados pelas instâncias ordinárias"19. Antecipar essa importante etapa da eleição certamente viabilizará o encurtamento do adiamento das eleições.

4) A suspensão de todo o calendário eleitoral após 15 de agosto de 2020, faria com que a data de referência para tais prazo fosse o dia da eleição, que ainda não está definido. Assim, quando a data do pleito fosse definida, haveriam de ser reiniciados tais prazos, o que fatalmente prorrogaria ainda mais a realização da eleição. Restam justificadas, portanto, as exceções de suspensão de prazo $^{20}$.

\footnotetext{
${ }^{15}$ Plataforma disponível no sítio eletrônico do TSE em: http://www.tse.jus.br/partidos/filiacao-partidaria/filiaweb. Acesso em 01 mai. 2020.

${ }^{16} \mathrm{CF}$. Art. 16. A lei que alterar o processo eleitoral entrará em vigor na data de sua publicação, não se aplicando à eleição que ocorra até um ano da data de sua vigência.

${ }^{17}$ Art. 14 omissis. (...) $\S 9^{\circ}$ Lei complementar estabelecerá outros casos de inelegibilidade e os prazos de sua cessação, a fim de proteger a probidade administrativa, a moralidade para exercício de mandato considerada vida pregressa do candidato, e a normalidade e legitimidade das eleições contra a influência do poder econômico ou o abuso do exercício de função, cargo ou emprego na administração direta ou indireta.

${ }^{18}$ Estabelece, de acordo com o art. 14, $\S 9^{\circ}$ da Constituição Federal, casos de inelegibilidade, prazos de cessação, e determina outras providências.

${ }^{19}$ Lei no $9.504 / 1997$, art. 16, § $1^{\circ}$.

${ }^{20}$ Processos judiciais; das regras que visam impedir o abuso de poder econômico e político; abuso de poder e uso indevido de meios de comunicação social; e condutas vedadas a agentes públicos
} 
5) A adoção do modelo proposto implicará na maior promoção de segurança jurídica, por meio da criação de um mandamento constitucional transitório, que pela força hierárquica da Constituição Federal, resguardando as normas vigentes ${ }^{21}$ para quando vencermos definitivamente a pandemia.

Importante destacar a urgência da atuação do Poder Constituinte Derivado em ofertar uma solução em relação a realização do pleito municipal do corrente ano. O Supremo Tribunal, em decisão da relatoria do Ministro Gilmar Mendes (2011) acerca do já citado artigo 16 da Magna Carta, assinalou:

\begin{abstract}
A competição eleitoral se inicia exatamente um ano antes da data das eleições e, nesse interregno, o art. 16 da Constituição exige que qualquer modificação nas regras do jogo não terá eficácia imediata para o pleito em curso. (...) Toda limitação legal ao direito de sufrágio passivo, isto é, qualquer restrição legal à elegibilidade do cidadão constitui uma limitação da igualdade de oportunidades na competição eleitoral. (...) A jurisdição constitucional cumpre a sua função quando aplica rigorosamente, sem subterfúgios calcados em considerações subjetivas de moralidade, o princípio da anterioridade eleitoral previsto no art. 16 da Constituição, pois essa norma constitui uma garantia da minoria, portanto, uma barreira contra a atuação sempre ameaçadora da maioria.
\end{abstract}

\title{
5. Conclusões
}

Após as considerações feitas ao longo deste trabalho, é possível responder à perguntaproblema da pesquisa ora proposta: como adiar as eleições municipais, em razão da pandemia, conciliando a saúde pública com a legitimidade do pleito, resguardando a ordem constitucional?

Eis a alternativa, aprovação de uma PEC, incluindo dispositivo nos Atos das Disposições Constitucionais Transitórias (ADCT), autorizando que o TSE, se necessário em razão da pandemia, adie as eleições municipais, tão somente enquanto perdurar o estado de emergência em saúde causado pelo coronavírus ou até que exista meios seguros de viabilizar as eleições, do ponto de vista da saúde pública e segurança jurídica.

${ }^{21}$ Exemplo: Lei Federal no 9.504/97. Art. 105. Até o dia 5 de março do ano da eleição, o Tribunal Superior Eleitoral, atendendo ao caráter regulamentar e sem restringir direitos ou estabelecer sanções distintas das previstas nesta Lei, poderá expedir todas as instruções necessárias para sua fiel execução, ouvidos, previamente, em audiência pública, os delegados ou representantes dos partidos políticos. (...) $\S 3^{\circ}$ Serão aplicáveis ao pleito eleitoral imediatamente seguinte apenas as resoluções publicadas até a data referida no caput. 
Rememoremos os necessários contornos de solução proposta: cumprimento do calendário eleitoral, em seu formato original, até o dia 15 de agosto de 2020, suspendendo-se o calendário eleitoral a partir de então (a exceção dos prazos relativos a: processos judiciais; das regras que visam impedir o abuso de poder econômico e político; abuso de poder e uso indevido de meios de comunicação social; e condutas vedadas a agentes públicos); suspendendo a aplicabilidade dos dispositivos legais contrariados pelo sugerido artigo da ADCT, suspensão tão somente para a eleição municipal que está prevista para 2020.

Nossa geração não vivenciou uma eleição e pandemia simultaneamente. Qualquer resposta que seja ofertada diante do problema proposto ensejará discussões, aliados e opositores à referida tese. A pretensão maior deste trabalho é fomentar o debate, propondo apenas um esboço de solução.

O Congresso Nacional terá o protagonismo na construção da solução do caso apresentado, por meio de seu Poder Constituinte Derivado. O TSE certamente contribuirá e pressionará para que o desfecho se coadune com o entendimento da Corte Eleitoral, que é a instituição responsável pela realização do pleito. O STF, por fim, provavelmente atuará em resposta aos insatisfeitos com o modelo aprovado de emenda à Constituição.

Enquanto isso, a pandemia ceifa vidas, o estrangulamento da economia leva a falência empresas, promove desemprego, o Governo Central vive um momento de grande instabilidade, tudo isso dito para concluir que nossa democracia está em risco. O direito à vida precisa ser garantido, como também a democracia e ordem constitucional, ambos implementados na realização da eleição municipal, que acontecerá, só ainda não sabemos quando.

\section{Referências}

AGRA, Walber de Moura. A possibilidade de adiamento das eleições municipais. Revista Consultor Jurídico. 31 mar. 2020, Disponível em: https://www.conjur.com.br/2020-mar31/moura-agra-possibilidade-adiamento-eleicoes\#_ftn3. Acesso em 02. mai. 2020.

ALEXY, Robert. Teoria dos direitos fundamentais. Trad.; Virgílio Afonso da Silva. São Paulo: Malheiros, 2008.

ASSOCIAÇÃO DOS MAGISTRADOS BRASILEIROS. Ministro Barroso dá aula de democracia e adianta ações após posse na presidência do TSE. Disponível em:

https://www.amb.com.br/live-ministro-barroso-da-aula-de-democracia-e-adianta-acoes-apos- 
posse-na-presidencia-do-tse/?doing_wp_cron $=1588413596.9756810665130615234375$. Acesso em: 02 mai. 2020.

ÁVILA, Humberto. Teoria dos princípios: da definição à aplicação dos princípios jurídicos. 4.ed. rev. São Paulo: Malheiros, 2005.

BARREIROS NETO, Jaime. Os Impactos do COVID-19 nas Eleições 2020 e a Proposta de Unificação do Calendário Eleitoral. In: BAHIA, Saulo José Casali (org.). Direitos e deveres fundamentais em tempos de coronavírus. São Paulo: Editora Iasp, 2020.

BRASIL, Senado Federal. Arquivo $S$ - Há 100 anos, gripe espanhola devastou país e matou presidente. 03 set. 2018. Disponível em:

https://www12.senado.leg.br/jovemsenador/home/noticias-1/externas/2018/09/ha-100-anosgripe-espanhola-devastou-pais-e-matou-presidente. Acesso em 01 mai. 2020.

BRASIL, Senado Federal. Wellington Fagundes propõe PEC para tornar coincidentes os mandatos eletivos. 03 abr. 2020-A. Disponível em:

https://www12.senado.leg.br/noticias/materias/2020/04/03/wellington-fagundes-propoe-pecpara-tornar-coincidentes-os-mandatos-eletivos. Acesso em: 02 de mai. 2020.

BRASIL. Supremo Tribunal Federal. Medida cautelar na ação direta de inconstitucionalidade 6.341/DF. Relator Ministro Marco Aurélio, Plenário. Disponibilizado em 24 mar. 2020-B.

BRASIL. Supremo Tribunal Federal. Recurso Extraordinário $n^{\circ}$ 633.703. Relator Ministro Gilmar Mendes, 23-3-2011, P, DJE de 18-11-2011, Tema 387. Disponível em:

http://www.stf.jus.br/portal/constituicao/artigoBd.asp\#visualizar. Acesso em 02 mai. 2020.

BRASIL. Tribunal Superior Eleitoral. Consulta $n^{o}$ 11.551. 2020-C. Relator Ministro Og Fernandes. Disponível em: https://pje.tse.jus.br:8443/pje-

web/ConsultaPublica/DetalheProcessoConsultaPublica/listView.seam?ca=1b8b4a6edae9c35e6 c5607d88776c82539b484d172d84d8e. Acesso em 30 abr. 2020.

BRASIL. Tribunal Superior Eleitoral. Normas e documentações. Disponível em: http://www.tse.jus.br/eleicoes/eleicoes-2020/normas-e-documentacoes. Acesso em 01 mai. 2020.

BRASIL. Tribunal Superior Eleitoral. Presidente do TSE reafirma que calendário eleitoral das Eleições 2020 está sendo cumprido. 29 mar. 2020. 2020-D. Disponível em:

http://www.tse.jus.br/imprensa/noticias-tse/2020/Marco/presidente-do-tse-reafirma-quecalendario-eleitoral-das-eleicoes-2020-esta-sendo-cumprido. Acesso em 02 mai. 2020.

FERNANDES, Rômulo Magalhães. Colisão de direitos: a liberdade de imprensa e os direitos da personalidade de crianças e adolescentes. Revista Direito e Liberdade - RDL - ESMARN v. 18, n. 3, p. 257-293, set./dez. 2016. Disponível em:

http://www.mpsp.mp.br/portal/page/portal/documentacao_e_divulgacao/doc_biblioteca/bibli_s ervicos_produtos/bibli_informativo/bibli_inf_2006/Rev-Dir-e-Liberd_v.18_n.03.09.pdf.

Acesso em: 02. mai. 2020. 
GOMES, José Jairo. Direito Eleitoral. 16. ed. São Paulo: Atlas, 2020.

ORGANIZAÇÃO PAN-AMERICANA DA SAÚDE (BRASIL). Folha informativa - COVID19 (doença causada pelo novo coronavírus). Brasília, 2020. Disponível em:

https://www.paho.org/bra/index.php?option=com_content $\&$ view=article \&id=6101: covid $19 \&$ It emid=875. Acesso em: 01 mai. 2020.

PERNAMBUCO. Decreto n ${ }^{\circ}$ 48.809, de 14 de março de 2020. Disponível em:

https://legis.alepe.pe.gov.br/texto.aspx?id=49417\&tipo=TEXTOATUALIZADO. Acesso em 01 de mai. 2020.

VEJA. Pandemia de coronavírus pode durar até dois anos, afirma estudo. 01 mai. 2020. Disponível em: https://veja.abril.com.br/saude/pandemia-de-coronavirus-provavelmentedurara-2-anos-dizem-especialistas/. Acesso em 02 de mai. 2020. 